Accepted for Publication January 2020: Journal of Thermal Analysis and Calorimetry https://doi.org/10.1007/s10973-019-09237-x

\section{Application of TG Technique to Determine Spontaneous Heating Propensity of Coals}

*Niroj Kumar Mohalik', Edward Lester ${ }^{2}$, and Ian S Lowndes ${ }^{2}$

${ }^{1}$ Scientist, Mine Ventilation Division, CSIR-Central Institute of Mining and Fuel Research, Barwa Road, Dhanbad, India

${ }^{2}$ Faculty of Engineering, University of Nottingham, University Park Campus, Nottingham, NG7 2RD, UK

(* Corresponding author: Niroj.mohalik@gmail.com)

\section{Abstract}

The TG method is applied to eleven coal samples of varying rank collected from across the Jharia coalfield, India to determine spontaneous heating susceptibility. Previous literature does not agree as to the TG experimental parameter that characterises the spontaneous heating susceptibility of coal. A series of TG experiments were performed on triplicate samples of each coal to determine the susceptibility of coal to spontaneous heating. Each prepared sample had the following properties: mass $-10 \mathrm{mg}$, size distribution $-212 \mu \mathrm{m}$, and were subjected to a sample gas flow rate of $40 \mathrm{ml} \mathrm{min}{ }^{-1}$ and a balance gas flow rate of $60 \mathrm{ml} \mathrm{min}^{-1}$ under the following four different heating rates: $1,5,15 \& 30$ ${ }^{\circ} \mathrm{C} \min ^{-1}$. The study concludes that the heating rate of $5^{\circ} \mathrm{C} \mathrm{min}^{-1}$ should be used to determine the spontaneous heating susceptibility. The experimental data obtained is subjected to chemo-metric tools i.e. principal component analysis (PCA) and hierarchical clustering analysis (HCA) to establish any linkage between the coal characteristics parameters and spontaneous heating susceptibility indices. These analyses reveal that the self-heating $\left(T_{s h}\right)$ and ignition temperature $\left(T_{i g n}\right)$ determined from the TG experiment results may indicate the susceptibility of coal to spontaneous heating, which is corroborated by well-established standard experiments as well as with field observations.

Keywords: Coal, Thermo-gravimetic Analysis (TG), Spontaneous Heating, Jharia coalfield,
Formatted: Normal, Don't adjust space between Latin and Asian text, Don't adjust space between Asian text and 
Accepted for Publication January 2020: Journal of Thermal Analysis and Calorimetry https://doi.org/10.1007/s10973-019-09237-x

\section{Highlights:}

- Development of an experimental method (i.e. experimental parameters) to determine spontaneous heating of coal.

- There is an increase in the mass of coal samples within the low-temperature zone $\left(200-350{ }^{\circ} \mathrm{C}\right)$ before the ignition point of the coal which may be due to oxygen adsorption at the surface.

- TG experiment results $\left(T_{s h}\right.$ and $\left.T_{i g n}\right)$ is an indicator to determine the spontaneous heating propensity of coals

- TG experiment results are statistically analyzed to explore the efficacy for its potential wider applicability

- Comparative study of the field observations, TG experiment and standard CPT results with subsequent statistical analysis corroborate the same conclusion
Formatted: Normal, Don't adjust space between Latin and Asian text, Don't adjust space between Asian text and 


\subsection{Introduction}

Over the last 140 years, the Indian coalfields have experienced a large number of extensive open and concealed fires[1]. Approximately $70 \%$ of these fires are due to spontaneous heating [2]which results in the loss of a key natural resource, which detrimentally impacts the national economy, health, and environment. Literature survey reveals that various researchers have adopted different methods to study the mechanism of spontaneous heating as well as to assess the propensity of coals towards spontaneous heating under laboratory conditions and the related field conditions[3-6]. Amongst these methods, three different thermal analysis techniques i.e. differential thermal analysis (DTA), differential scanning calorimetry (DSC) and thermogravimetric analysis (TG) are widely used to study coal characteristics, reactivity potential, compositional characteristics and propensity towards spontaneous heating. In thermal analysis studies, researchers have developed different techniques to determine the susceptibility of coal towards spontaneous heating [4, 5, 7-14]. Researchers standardize the experimental parameters of the DTA and DSC techniques to identify the susceptibility of coal to spontaneous heating. TG techniques have been applied by a few researchers to study the susceptibility of coal to spontaneous heating, but does not agree as to both the choice or change required in the experimental parameters to characterize the susceptibility of the coal to spontaneous heating[8]. TG studies of coal require the specification of the following experimental parameters: the mass of the coal sample, the particle size distribution of the sample, the reaction gas species, the flow rate of the reaction gas and the heating rate applied. There is a need to develop a standard experimental method in the use of TG methods to determine the proneness of coals to spontaneous heating of coal. The process of coal spontaneous combustion could be divided into four stages, including dehydration and desorption Stage, oxidation stage, combustion stage, and burnout stage. The mass-loss rates of coal were independent of heating rates below ignition temperatures but expanded and shifted to higher temperatures above ignition temperatures[15]. The coal quality significantly affected coal's oxidation in lowtemperature oxidation phase and coal samples with smaller sizes were more prone to combustion. At the lowtemperature stage, the coal sample size exerted no effect on coal's oxidation, at medium- and high-temperature stages, smaller coal sample sizes promoted coal's oxidation[16]. The thermal behaviour of weathered and fresh coal was analyzed and characteristic temperatures of fresh coal were higher than those of weathered coal. The total thermal energy generated from the exothermic onset temperature to $200{ }^{\circ} \mathrm{C}$ by weathered coal was much less than generated by fresh coal[17]. For the same coal sample, characteristic temperatures increase along with increasing heating rate and decrease along with increasing oxygen concentration. The effects of heating rate and oxygen concentration on the apparent activation energy of coal are not consistent [18]. For a coal sample subjected to TG analysis, following the initial removal of moisture, there is an observed increase in mass of the sample before a sudden inflexion in the mass curve particular in the coal oxidation process. [9-12, 19]. The key functional groups for this typical coal oxidation mass gain were carboxyl $(-\mathrm{COOH})$ and carbonyl $(-\mathrm{C}=0)[19]$. The smaller the mass gain, the lower the ignition temperature and the more susceptible is the coal to spontaneous ignition [20, 21]. The increase in mass observed is believed to be due to the absorption of oxygen and the forming of coal-oxy-complexes over the coal surface in different temperature zone as per the type of coal. The determined increase in mass and temperature zone data may be used to classify coal as either reactive or non-reactive [10]. 
This study investigates the application of TG techniques to a series of 11 coal samples of varying rank collected from across the Jharia coalfield, India. Initially, six coal samples were investigated over a range of experimental conditions for sample mass, flow rates, particle size, and heating rate to develop suitable experimental parameters for this study. TG experimental results were analyzed to identify an indicator to determine spontaneous combustion of coal. TG results are further statistically explored with results of other standard methods to determine its efficacy and potential for wider applicability.

\subsection{Material and Methods}

\subsection{Sample Collection and Characterisation}

Eleven coal sample was collected (using a channel and chip sampling method) from different coal seams within the Jharia coalfield (JCF), India. The selected coal seams were classified as both fiery and non-fiery [11]. The collected samples were subsequently crushed and sieved to less than -212 micron and placed in airtight polythene bags to minimize aerial oxidation. Amongst the eleven samples, the first five samples (sample number: 1, 2, 3, 4 and 5) have past field histories of fires \& spontaneous heating, and the remaining six coals possessing no history of active heating. Standard proximate, ultimate, petrographic analysis, crossing point temperature (CPT) and modified crossing point temperature $\left(C P T_{H R}\right)$ analyses were performed on each of the eleven coal samples, a summary of these results are shown in Table 1[22]. The crossing point temperature (Indian method - $C P T_{I}$ ) of coal samples were determined as per the Directorate General Mine Safety (DGMS) circular i.e. DGMS Cir.Tech.3/1975. A spontaneous combustion rig (sponcomb rig) comprises of a vertical furnace, sample holder, a number of thermocouples with their attachment were used to determine modified crossing point temperature. The experiments were carried out by heating $100 \mathrm{~g}$ of coal samples slowly @ $1{ }^{\circ} \mathrm{C} / \mathrm{min}$ in an atmospheric air flow rate of $200 \mathrm{mlmin}^{-1}$ up to $350{ }^{\circ} \mathrm{C}$. The derivative of coal bed temperature will give a trigger point of the reaction known as modified crossing point temperature i.e. $C P T_{H R}$ (temperature where $d T / d t$ is equal to $2.0^{\circ} \mathrm{C} \mathrm{min}^{-1}$ because the heating rate is double of programmed temperature $1{ }^{\circ} \mathrm{C} \mathrm{min}^{-1}$ ) [22].

\subsection{TG Experimental Methods}

Subsequently, TG experiments were performed on the prepared coal samples using a PyrisTG1 instrument of M/s Perkin Almer. The low-temperature oxidation of coal depends upon the mass of the sample, the size fraction of the sample, the atmosphere of reaction, the flow rate of purging gas, the heating rate, and temperature range. Initially, six samples were investigated over a range of experimental conditions, namely: (1) three different masses of sample i.e. 10,20 and $30 \mathrm{mg}$; (2) three different flow rates of the purge gas i.e. 20,40 and $80 \mathrm{ml} \mathrm{min}^{-1}$; (3) three different particle size distributions of the sample i.e. $-212+105,-105+75,-75 \mu \mathrm{m}$; (4) four different heating rates i.e. $1,5,15$ and $30{ }^{\circ} \mathrm{C}$ $\mathrm{min}^{-1}$. Each experiment is repeated twice to confirm repeatability and the standard error mean for heating rate $30{ }^{\circ} \mathrm{C}$ $\mathrm{min}^{-1}$ varies from 0.4 to 5.7. Total of 78 experiments were carried out for this study excluding repeats. An example of the results obtained for coal sample 1 subjected to the experimental parameter matrix changes described above are given in Fig.1 (a), (b), (c), (d) with the details being presented in the appendix (Figs. A1 to A4).

The results of initial experiments for all six fiery coal samples concludes the following observations: 
- $\quad$ Mass, particle size of samples and purging gas flow rate plays an important role. The peak temperature is proportional to the mass of the sample.

- The peak widths are sharper as the particle size becomes finer and the peak temperature is shifted depending upon the samples.

- $\quad$ The DTG curves exhibit a shift and some of the samples are not fully combusted at low purge gas flow rates. It also depends upon the heating rate.

Taking the above observations into account it was decided to keep the following experimental parameters constant: the mass of the sample $10 \mathrm{mg}$; flow rate of purging gas (air) $40 \mathrm{cc} \mathrm{min}^{-1}$; particle size of the sample $-212 \mu \mathrm{m}$; temperature range 30 to $920^{\circ} \mathrm{C}$; and to only vary the rate of heating for the final TG study of all the samples. Each experiment is repeated three times for repeatability and a total of 132 experiments were carried out for this study.

\subsection{Spontaneous heating propensity study}

The spontaneous heating propensity of a coal sample determines when the initial reaction takes place, the reaction span, the rate of reaction and physiochemical reactions. A critical study of TG curve reveals there is an increase in mass i.e. maximum mass gain $\left(W_{m w g}\right)$ concerning its previous mass within an identified temperature range (Fig. 2). The maximum mass gain $\left(W_{m w g}\right)$ of a sample is determined from the differential mass of the sample temperature at which mass increases or by the determination of the initial reaction $\left(T_{i r}\right)$ to maximum mass gain temperature $\left(T_{m w g}\right)$ at which the initial reaction finishes. First-order derivatives of a TG curve, known as Differential Thermo Gravimetric (DTG) curves of all of the sample were calculated to determine the self-heating temperature $\left(T_{s h}\right)$ or minimum $\mathrm{dW} / \mathrm{dt}$ temperature $\left(T_{s h}\right)=0.1, d W / d t$ for ignition temperature $\left(T_{i g n}\right)$ (Fig. 3). The results of the above experiments for all eleven coal samples are given in Fig. 4a-e.

An analysis of the results obtained from the spontaneous heating study for all coal samples at five different heating rates is presented on Fig. 4. The initial reaction temperature $\left(T_{i r}\right)$ for all of the samples across the five different heating rates lies within the temperature range of $100{ }^{\circ} \mathrm{C}$ to $300{ }^{\circ} \mathrm{C}$ (Fig. $4 \mathrm{a}$ ). The $T_{i r}$ varies from $105{ }^{\circ} \mathrm{C}$ (sample 2 : HR-1 ${ }^{\circ} \mathrm{C}$ $\min ^{-1}$ ) to $285^{\circ} \mathrm{C}$ (sample 7: $\mathrm{HR} 30^{\circ} \mathrm{C} \mathrm{min}^{-1}$ ). The observed $T_{i r}$ values are directly proportional to the applied heating rates, across the range of 1 to $30^{\circ} \mathrm{C} \mathrm{min}^{-1}$. There is a measured mass gain $\left(W_{m w g}\right)$ for all of the samples tested subjected to the four different heating rates within the temperature range of 100 to $400{ }^{\circ} \mathrm{C}$ (Fig. 4b) [10, 20]. The $W_{m w g}$ is very high at slow heating rates and low at a higher heating rate. The observed mass gain is inversely proportional to the heating rate between the ranges 1 to $30{ }^{\circ} \mathrm{C} \mathrm{min}^{-1}$. The $W_{m w g}$ varies from $0.09 \%$ (sample 6: HR-30) to $3.19 \%$ (sample 3: HR-1). The samples 1, 2 and 3 exhibit the lower $W_{m w g}$ values, whereas samples number 5, 6, 9 and 10 have higher values. The maximum mass gain temperature $\left(T_{m w g}\right)$ for all of the samples in different heating rates within the temperature range of $288^{\circ} \mathrm{C}$ (sample 3 : HR-1 ${ }^{\circ} \mathrm{C} \mathrm{min}{ }^{-1}$ ) to $375^{\circ} \mathrm{C}$ (sample 5: HR $30^{\circ} \mathrm{C} \mathrm{min}^{-1}$ ) (Fig. $4 \mathrm{c}$ ). The observed $T_{m w g}$ values are directly proportional to the applied heating rates, across the range of 1 to $30{ }^{\circ} \mathrm{C} \mathrm{min}{ }^{-1}$. The self-heating temperatures $\left(T_{s h}\right)$ for all of the samples across the different applied heating rates lie within the temperature range of $200{ }^{\circ} \mathrm{C}$ to $350{ }^{\circ} \mathrm{C}$ (Fig. 4d). The $T_{s h}$ varies from a minimum of $249^{\circ} \mathrm{C}$ (sample 3: HR-1) to a maximum of $331{ }^{\circ} \mathrm{C}$ (sample 5: HR-30). Except of the sample numbers 2, 8, 10, $\left(\mathrm{HR}-1{ }^{\circ} \mathrm{C} \min ^{-1}\right)$ and $9\left(\mathrm{HR}-30{ }^{\circ} \mathrm{C} \mathrm{min}{ }^{-1}\right)$ the measured $T_{\text {sh }}$ values are directly proportional to the heating rates between the ranges 1 to $30{ }^{\circ} \mathrm{C} \mathrm{min}-1$. The samples 1,2 and 3 
exhibits the lower $T_{s h}$ values, whereas sample number 5, 6,9 and 10 have relatively higher values. Across all of the applied heating rates, the ignition temperatures values $\left(T_{i g n}\right)$ for all of the samples lie within the temperature range of $300{ }^{\circ} \mathrm{C}$ to $400{ }^{\circ} \mathrm{C}$ (Fig. 4 e). The $T_{i g n}$ values vary from a minimum of $321{ }^{\circ} \mathrm{C}$ (sample 3: HR-5) to $378{ }^{\circ} \mathrm{C}$ (sample 5: HR-30). The observed $T_{s h}$ value is high for the heating rate $1^{\circ} \mathrm{C} \mathrm{min}^{-1}$ as compared to heating rate $5{ }^{\circ} \mathrm{C} \mathrm{min}{ }^{-1}$ and directly proportional to the heating rate between the ranges 5 to $30^{\circ} \mathrm{C} \mathrm{min}^{-1}$. The samples 1,2 and 3 exhibits the lower $T_{s h}$ values, whereas sample numbers 5, 6,9 and 10 have relatively higher values. Above results reveals that the analysis data $\left(T_{i r}, W_{m w g}, T_{m w g}, T_{s h}\right.$, and $\left.T_{i g n}\right)$ from TG and DTG curves for heating rate $5{ }^{\circ} \mathrm{C} \mathrm{min}^{-1}$ gives a better indicator to study of spontaneous heating of coal. The same results are subjected to further statistical analysis.

\subsection{Data Treatment and Chemo-metric analysis}

Statistical treatment of data including correlation analysis and multivariate analysis (i.e. Principal component analysis (PCA) and Hierarchical clustering analysis (HCA)) were carried out using Statistica-7 to determine the relationship between the TG experimental data sets described in the previous section [23, 24]. Correlation studies were performed to identify any potential relationships between the different spontaneous heating susceptibility indices (seven independent variables - $C P T_{l}, C P T_{H R}, T_{i r}, W_{m w g}, T_{m w g}, T_{s h}$, and $T_{i g n}$ ) and the coal characteristic data, independently provided by the proximate, elemental and petrographic analyses conducted on the coal samples (fourteen dependent variables- $M, A_{d}, V M_{d}, F C_{d}, C_{d}, H_{d}, N_{d}, S_{d}, O_{d}, V_{m}, L_{m}, S F_{m}, F_{m}$, and $V R_{m}$, whose determined values are presented in Table 1. ). The values of the correlation coefficients determined ( $<<0.05$ confidence interval) for the above studies are presented in Table 2. The PCA analyses performed considered the relationships between the above fourteen proximate, elemental and petrographic variables with the seven susceptibility indices determined for each coal sample. For these analyses, the principal components (PCs) with Eigen values greater than 2.0 were considered. The eigenvalues of the first three PCs are given in Table 3 and the projections of these variables on the factor plane (1x2) and (1x3) are depicted in Fig. 5. Hierarchical clustering techniques have been applied to classify the coal tested using the Euclidian distance method (average linkage method). The hierarchal clustering (joining tree) was identified using the above mentioned independent variables and dependent variables. The dendograms obtained from HCA analyses for each of the seven spontaneous heating indices are presented in Figs. 6 (a) to (g), respectively.

A study of the data presented in Table 2 reveals that $C P T_{H R}, T_{s h}$ and $T_{i g n}$, possess the highest significance with the ash content (AC) ( $\mathrm{r}=0.87$ to -0.94$)$ and the volatile matter (VM) $(\mathrm{r}=-0.81$ to -0.93$)$. A subsequent PCA analysis reveals a cumulative variance for the first three PCs are found to be more than $80.01 \%$, and for the remaining PCs is very small $(<10)$ (Table 3). The eigenvalues of these three PCs, modify the magnitude of the corresponding eigenvectors significantly (Table 3). The projection of the variables on the factor plane $1 \times 2$ and factorial plane $1 \times 3$ shows that first group i.e. $C P T_{l}, C P T_{H R}, T_{m w g}, T_{s h}$, and $T_{i g n}, M, A_{d}$ are opposite and far from the centre to $M, V M_{d}, F C_{d}, C_{d}, H_{d}, O_{d}$, which signifies they are negatively correlated. It was also observed that the above two groups are spatially grouped, which signifies that a significant correlation between them. The number of clusters obtained from the dendograms for these seven cases is 3, which indicates that the identified clusters are natural (Fig. 6). All the samples are forced to one cluster at a linkage distance of approximately 50 except one 80 (Fig. 6). If the number of clusters remains the same (i.e. 3) then the linkage distance could be achieved as a linkage distance of 22, 24, 33, 20, 22, 21 and 22 
respectively. Consequently, it may be concluded that in all cases three clusters are chosen for the classification of coals seams. The details of the clusters so identified from the dendograms for coal samples tested are summarised in Table 4. An analysis of this table reveals that $C P T_{l}, C P T_{H R}, T_{s h}$, and $T_{i g n}$ have same sample number in all three clusters. The eleven coal samples studied were divided into three categories as per their susceptibility to self-heating i.e. low (first cluster: coal samples 1, 2, $3 \& 4$ ), medium (second cluster: coal samples 6, 7, 8, 9 \& 10) and high (third cluster: coal samples 5). The samples 1,2, 3 and 4 have been identified as being more prone to spontaneous heating from the experimental investigation which is further confirmed by the cluster analysis.

\subsection{Validation of results with $\mathrm{CPT}_{\mathrm{I}}$ and $\mathrm{CPT}_{\mathrm{HR}}$}

The correlation studies were carried out among selected seven spontaneous heating susceptibility indices and the results summarized in Table 5. It is observed that the crossing point temperatures $\left(C P T_{I}\right.$ and $\left.C P T_{H R}\right)$ have a positive correlation with $T_{m w g}, T_{s h}$, and $T_{i g n}$. Among these three spontaneous heating susceptibility indices from TG experiments, $T_{s h}$ and $T_{i g n}$ possess a stronger correlation with both $C P T_{I}$ and $C P T_{H R}$. It is further concluded that the $C P T_{I}$ and $C P T_{H R}$ values are proportional to $T_{s h}$ where the correlation coefficient between these two parameters is found to be 0.82 and 0.91 , respectively (Table 5 and Fig. 7). Similarly, it is concluded that the $C P T_{I}$ and $C P T_{H R}$ values are proportional to $T_{i g n}$ (where the correlation coefficient between these two parameters is found to be 0.76 and 0.93 , respectively). Above study recaps that sample number 1, 2, 3 and 4 exhibit actual experimentally measurable characteristics and confirmed the occurrence of the fire at operating or closed mines (Table 1). The combined evidence provided by an examination of all of the experimental results, and the subsequent statistical analyses performed on these data sets and the aforementioned field observations, corroborate the same conclusions. Consequently, it is proposed that the self-heating $\left(T_{s h}\right)$, and ignition $\left(T_{i g n}\right)$ temperatures determined from TG analyses of coal may be used to determine the susceptibility of a coal to spontaneous heating.

\subsection{Conclusions}

The results obtained from the TG have been used to study coal characteristics for the last several decades. Several studies have been carried out to determine the spontaneous heating of coals. However, the application of this method requires the identification of a set of experimental parameters to determine the spontaneous heating of coal.

An extensive study of six fiery coal samples was conducted in an attempt to identify the appropriate experimental parameters. These parameters included sample fraction size, the mass of sample, flow rate, and heating rate. The result of the above study reveals that the following experimental parameters (sample size $-212 \mu \mathrm{m}$, the mass of sample - 10 mg and flow rate $-40 \mathrm{ml} \mathrm{min}{ }^{-1}$ sample gas and $60 \mathrm{ml} \mathrm{min}{ }^{-1}$ balance gas, heating rate $5{ }^{\circ} \mathrm{C} \mathrm{min}^{-1}$ ) were suitable to assess the spontaneous heating susceptibility of coals.

TG experimental results reveals there is an increase in the mass within the low-temperature zone $\left(200-350{ }^{\circ} \mathrm{C}\right)$ before the ignition point of the coal. The increase in mass gain of coal samples may be due to oxygen adsorption at the surface $[10,20]$. The maximum mass gain is inversely proportional to the heating rate.

The TG experiments results are further statistically analysed to explore the efficacy for its potential wider applicability. The basic correlation study, PCA and HCA reveal that the constituent of proximate analysis (A, VM and FC) shows 
a better correlation with the results of TG experiments and CPT experiments. The TG experiment results $\left(T_{s h}\right.$ and $\left.T_{i g n}\right)$ may be considered as an indicator for determination of spontaneous heating of coals.

The hierarchical clustering has been applied for classification of coal seams. The coal samples collected from different seams can be categorized into three clusters, viz. highly susceptible, moderately susceptible and poorly susceptible. A comparative study of the field observations, TG experiment results and standard CPT results with subsequent statistical analysis corroborate the same conclusion.

\section{Acknowledgement}

Authors are grateful to Commonwealth Scholarship Commission, UK and The University of Nottingham for their financial support (Commonwealth Scholarship and Fellowship Plan -2010, INCS-2010-192). The authors are obliged to Ministry of Human Resources and Development, Government of India and Council of Scientific and Industrial Research (CSIR) for their kind permission to avail the above fellowship. Authors acknowledge thanks to Direct or, CSIR-CIMFR, all staffs of Mine Fire, Ventilation and Miner's Safety Research Group, CSIR-CIMFR for necessary help for the sample collection. 


\section{References}

1. Dhar, B.B., Keynote address on status of mine fires - Trends and challenges. In Proceedings of the Conference on Prevention and Control of Mine and Industrial Fires - Trends and Challenges, Calcutta, India, 1996: p. 1-8.

2. Zutshi, A., S.K. Ray, and B.C. Bhowmick, Indian coal vis-à-vis spontaneous heating problems. Journal of Mines, Metals \& Fuels, 2001. 44(5): p. 123-128.

3. Banerjee, S.C., Prevention and combating mine fires. Oxford and IBH Publishing Co. Pvt. Ltd., 2000: p. 33.

4. Banerjee, S.C. and R.N. Chakraborty, Use of DTA in the study of spontaneous combustion of coal. Journal of Mines Metals and Fuels, 1967. 15: p. 1-5.

5. Mohalik, N.K., E. Lester, and I.S. Lowndes, Review of experimental methods to determine spontaneous combustion susceptibility of coal - Indian context. International Journal of Mining, Reclamation and Environment, 2016: p. 1-32.

6. Kok, M., Recent developments in the application of thermal analysis techniques in fossil fuels. Journal of Thermal Analysis and Calorimetry, 2008. 91(3): p. 763-773.

7. Mohalik, N.K., D.C. Panigrahi, and V.K. Singh, An investigation to optimise the experimental parameters of differential scanning calorimetry method to predict the susceptibility of coal to spontaneous heating Archives of Mining Sciences 2010. 55(3): p. 669-689.

8. Mohalik, N.K., D.C. Panigrahi, and V.K. Singh, Application of thermal analysis techniques to assess proneness of coal to spontaneous heating. Journal of Thermal Analysis and Calorimetry, 2009. 98(2): p. 507-519.

9. Marinov (b), V.N., Self-ignition and mechanisms of interaction of coal with oxygen at low temperatures. 2. Changes in weight and thermal effects on gradual heating of coal in air in the range $20-300^{\circ} \mathrm{C}$. Fuel, 1977. 56(2): p. 158-164.

10. Marinov (a), V.N., Self-ignition and mechanisms of interaction of coal with oxygen at low temperatures. 1. Changes in the composition of coal heated at constant rate to $250{ }^{\circ} \mathrm{C}$ in air. Fuel, 1977. 56(2): p. 153-157.

11. Marinov (c), V.N., Self-ignition and mechanisms of interaction of coal with oxygen at low temperatures. 3. Changes in the composition of coal heated in air at $60{ }^{\circ} \mathrm{C}$. Fuel, 1977. 56(2): p. 165-170.

12. Marinov, S.P., et al., Combustion behaviour of some biodesulphurized coals assessed by TGA/DTA. Thermochimica Acta, 2010. 497(1-2): p. 46-51.

13. Mahajan, O.P. and P.L. Walker Jr, Water adsorption on coals. Fuel, 1971. 50(3): p. 308-317.

14. Kok, M.V., Simultaneous thermogravimetry-calorimetry study on the combustion of coal samples: Effect of heating rate. Energy Conversion and Management, 2012. 53(1): p. 40-44.

15. Zhang, Y., et al., Characteristics of mass, heat and gaseous products during coal spontaneous combustion using TG/DSC-FTIR technology. Journal of Thermal Analysis and Calorimetry, 2017

16. Zeng, Q., Y. Pu, and Z. Cao, Kinetics of oxidation and spontaneous combustion of major super-thick coal seam in Eastern Junggar Coalfield, Xinjiang, China. Journal of Loss Prevention in the Process Industries, 2018. 56: p. 128-136.

17. Deng, J., et al., Gases and thermal behavior during high-temperature oxidation of weathered coal. Journal of Thermal Analysis and Calorimetry, 2019.

18. Gao, J., M. Chang, and J. Shen, Comparison of bituminous coal apparent activation energy in different heating rates and oxygen concentrations based on thermo gravimetric analysis. Journal of Thermal Analysis and Calorimetry, 2017. 130(2): p. 1181-1189. 
19. Wang, K., et al., Kinetics and mechanisms of coal oxidation mass gain phenomenon by TG-FTIR and in situ IR analysis. Journal of Thermal Analysis and Calorimetry, 2018. 132(1): p. 591-598.

20. Avila, C.R., Predicting self-oxidation of coals and coal/biomass blends using thermal and optical methods. PhD thesis, University of Nottingham., 2012.

21. Avila, C., T. Wu, and E. Lester, Estimating the Spontaneous Combustion Potential of Coals Using Thermogravimetric Analysis. 2014.

22. Mohalik, N.K., E. Lester, and I.S. Lowndes, Development a modified crossing point temperature (CPTHR) method to assess spontaneous combustion propensity of coal and its chemo-metric analysis. Journal of Loss Prevention in the Process Industries, 2018.

23. Rencher, A.C., Methods of Multivariate Analysis. A JOHN WILEY \& SONS, INC. PUBLICATION, 2002.

24. STATISTICA-7.0, Electronic mannual statistica 7. 2004. 
Accepted for Publication January 2020: Journal of Thermal Analysis and Calorimetry https://doi.org/10.1007/s10973-019-09237-x

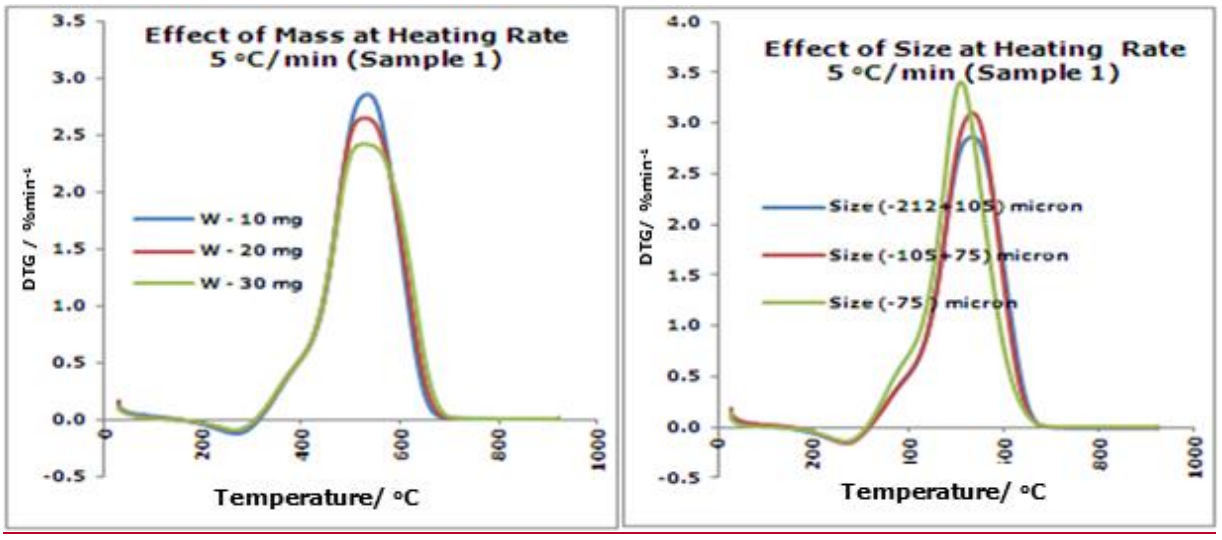

(a) Different mass of sample

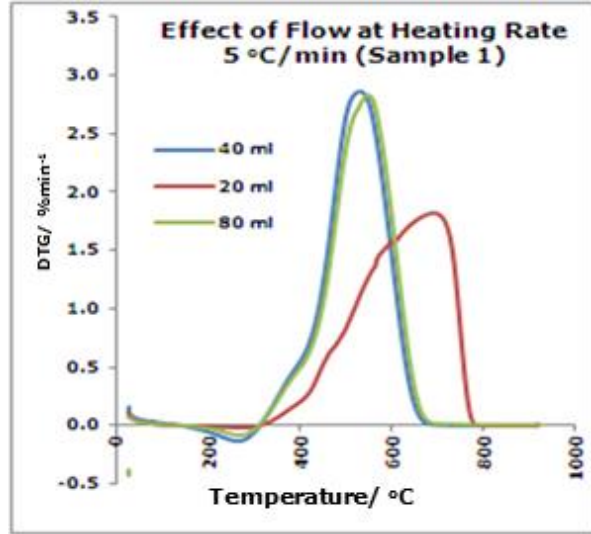

(b) Different fraction size of sample

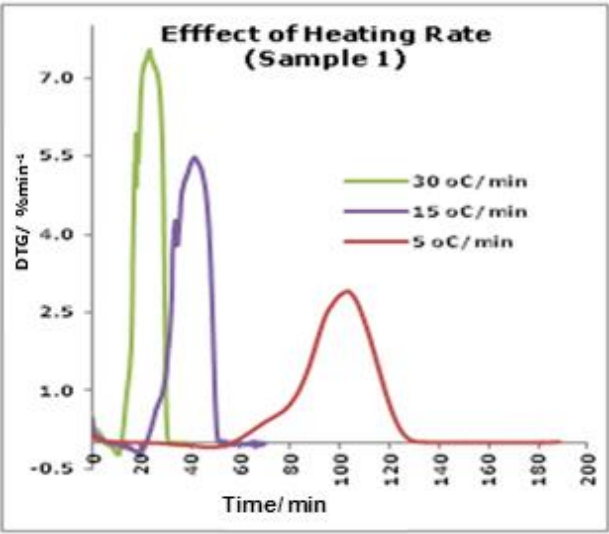

(c) Different flow rate for reaction

(d) Different heating rate for reaction

Fig. 1 DTG curve for sample 1 in different experimental parameters
Formatted: Normal, Don't adjust space between Latin and Asian text, Don't adjust space between Asian text and 
Accepted for Publication January 2020: Journal of Thermal Analysis and Calorimetry https://doi.org/10.1007/s10973-019-09237-x

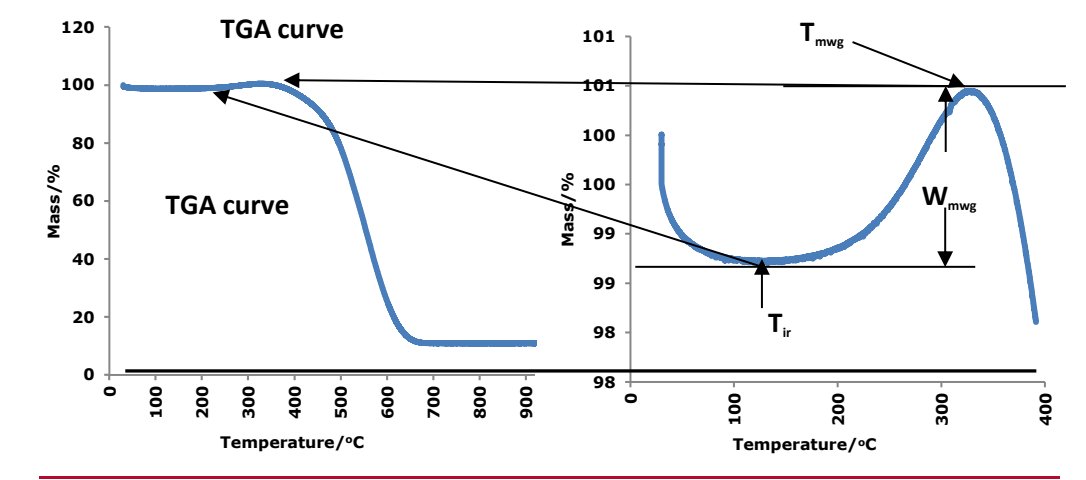

Fig. 2 TGA curve and weight changes in TGA curve (Sample 1)

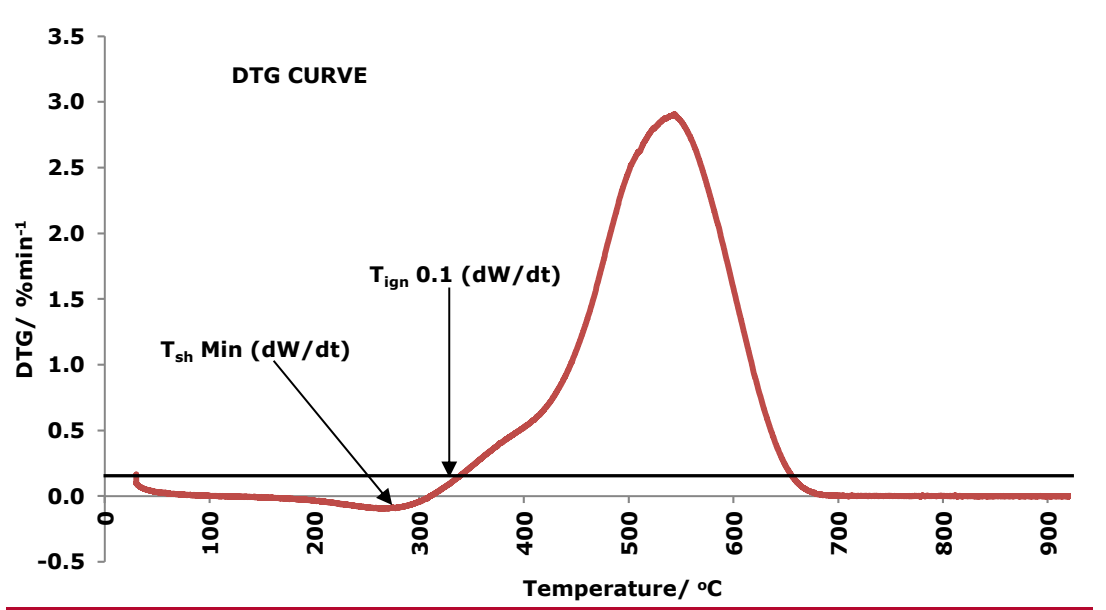

Fig. 3 DTG curve and different characteristics temperatures (Sample 1)
Formatted: Normal, Don't adjust space between Latin and Asian text, Don't adjust space between Asian text and 
Accepted for Publication January 2020: Journal of Thermal Analysis and Calorimetry https://doi.org/10.1007/s10973-019-09237-x

\section{Initial Reaction Temperature $\left(\mathrm{T}_{\mathrm{ir}}\right)$}

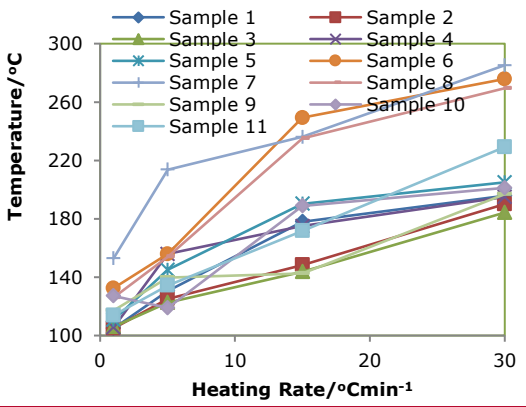

(a)

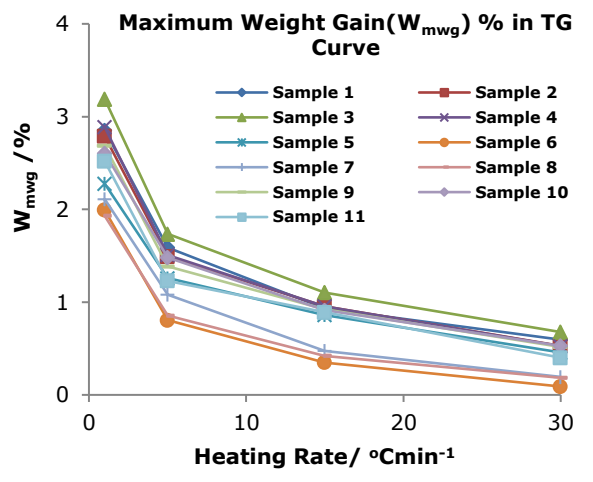

(b)
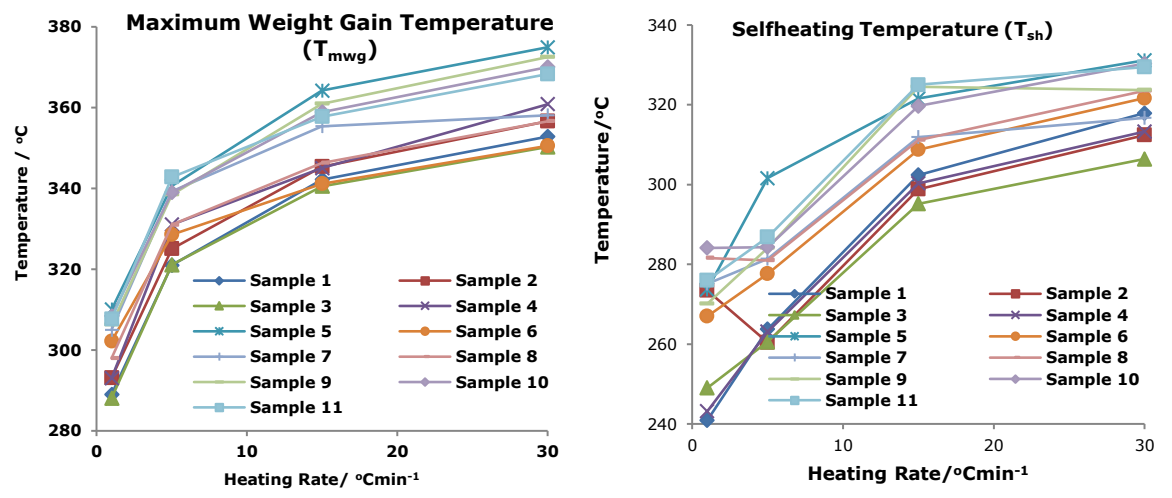

(c)

(d)

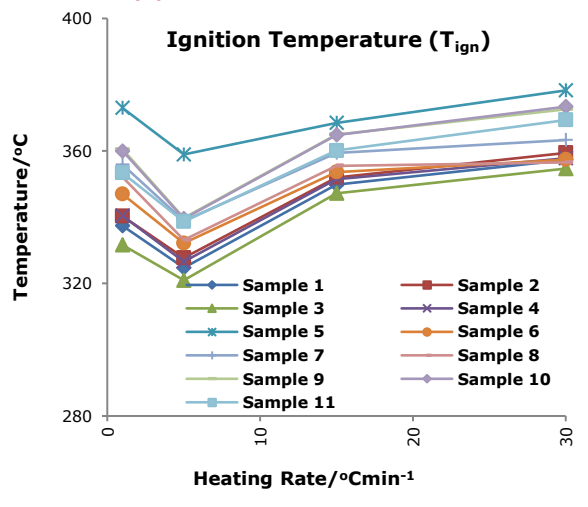

(e)

Fig. 4 Results of TGA and DTG Curves ( $\left.T_{i r}, W_{m w g}, T_{m w g}, T_{s h} \& T_{i g n}\right)$ of all the coal samples subjected to the five different applied heating rates $\left(1,5,10,15,30^{\circ} \mathrm{Cmin}^{-1}\right)$. 
Accepted for Publication January 2020: Journal of Thermal Analysis and Calorimetry https://doi.org/10.1007/s10973-019-09237-x
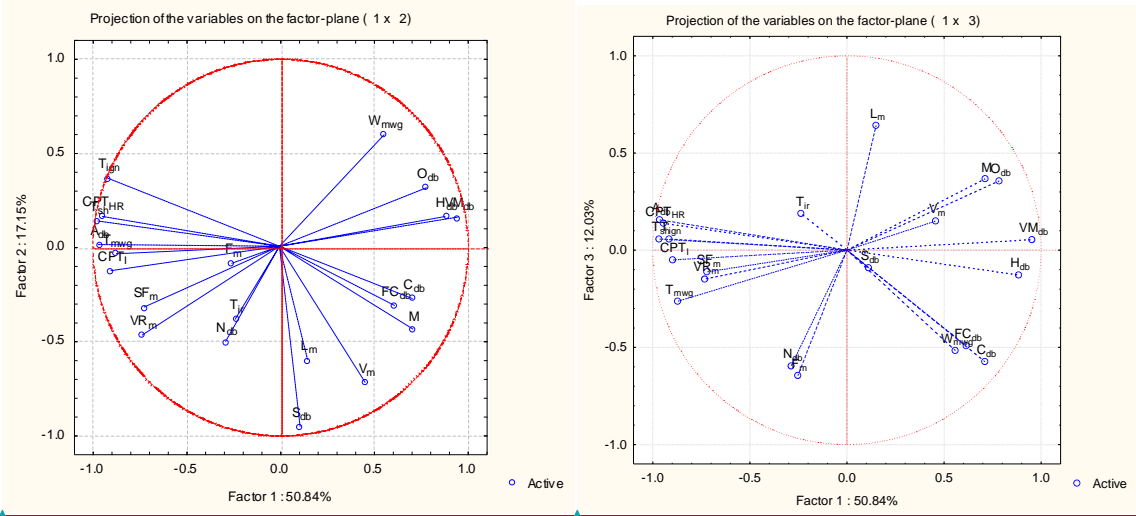

Fig. 5 PCA Results of Spontaneous heating susceptibility indices with basic coal characteristics

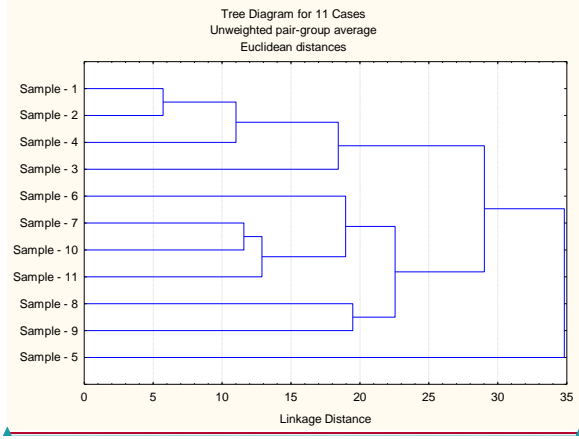

(a) $\mathrm{CPT}_{\mathrm{I}}$

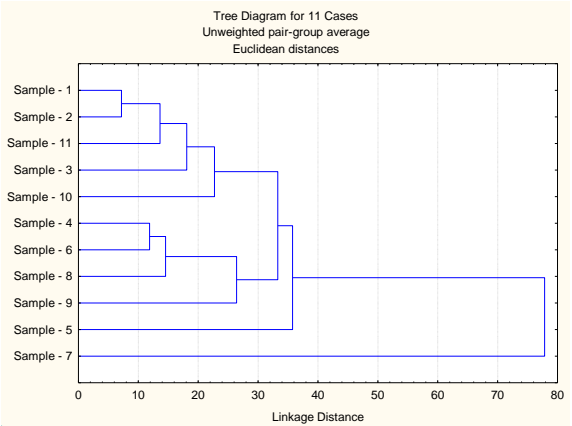

(c) $T_{\text {ir, }}$

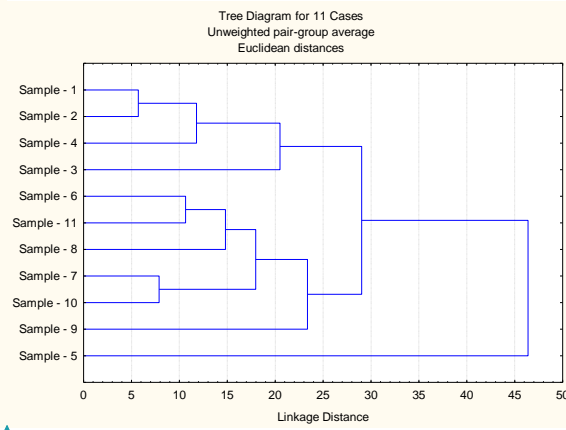

(b) $\mathrm{CPT}_{\mathrm{HR}}$

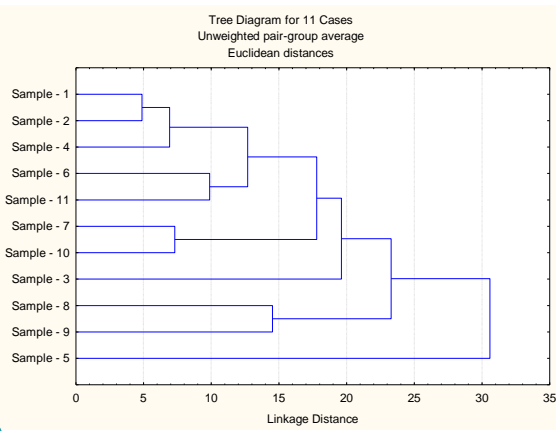

(d) $W_{\text {mwg, }}$
Formatted: Normal, Don't adjust space between Latin and Asian text, Don't adjust space between Asian text and

Field Code Changed

Field Code Changed

Field Code Changed

Field Code Changed

Field Code Changed

Field Code Changed 
Accepted for Publication January 2020: Journal of Thermal Analysis and Calorimetry https://doi.org/10.1007/s10973-019-09237-x
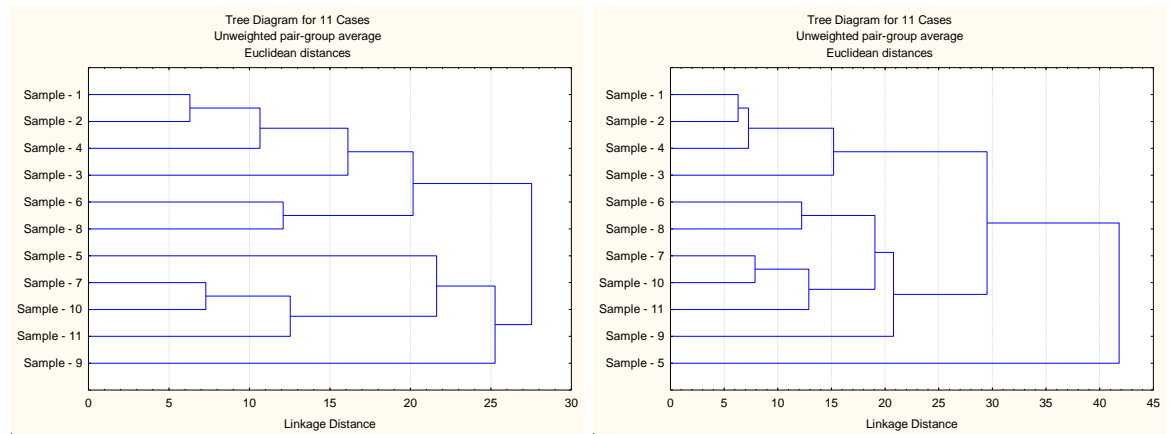

(e) Tmwg, (f) $\mathrm{T}_{\mathrm{sh}}$

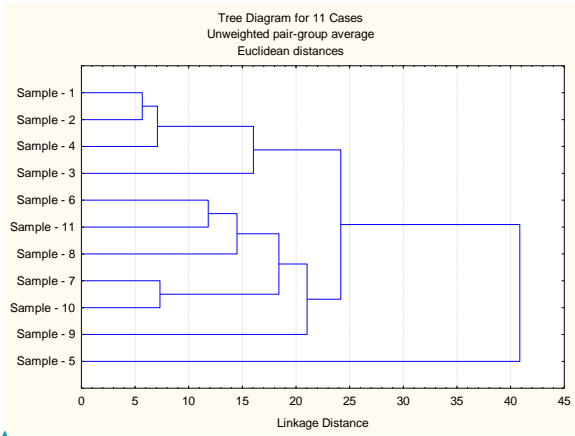

(g) $T_{\text {ign }}$

Fig. 6 HCA Results of spontaneous heating susceptibility indices with basic coal characteristics for classification of coal seams
Formatted: Normal, Don't adjust space between Latin and Asian text, Don't adjust space between Asian text and

\section{Field Code Changed}

Field Code Changed

\section{Field Code Changed}


Accepted for Publication January 2020: Journal of Thermal Analysis and Calorimetry https://doi.org/10.1007/s10973-019-09237-x

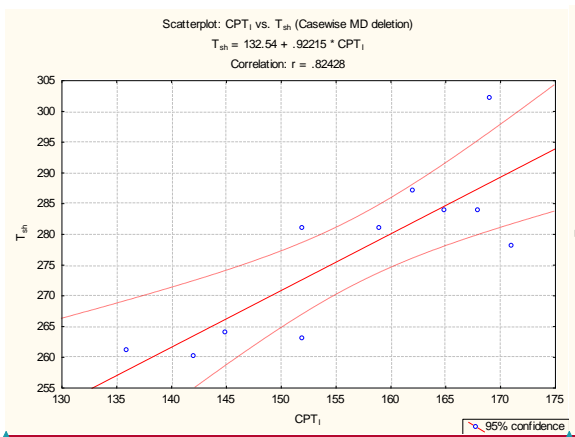

(a) $\mathrm{CPT}_{\mathrm{I}}$ vs $\mathrm{T}_{\mathrm{sh}}$

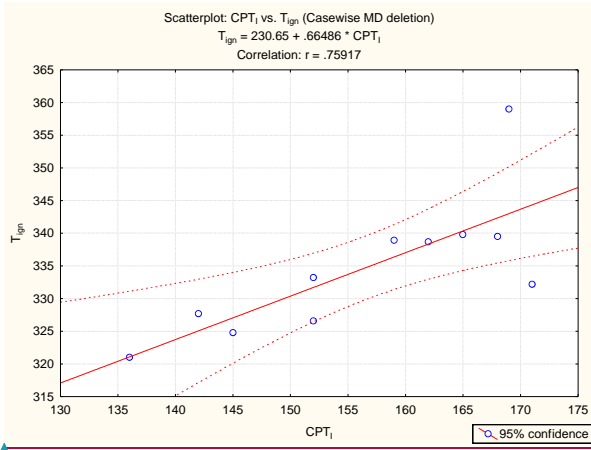

(c) $\mathrm{CPT}_{\mathrm{I}}$ vs Tign

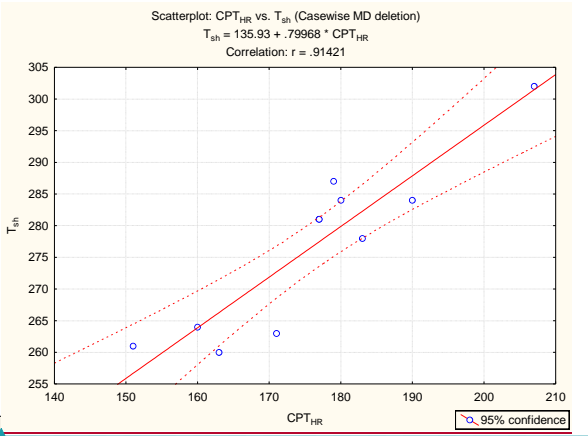

(b) CPTHR VS Tsh

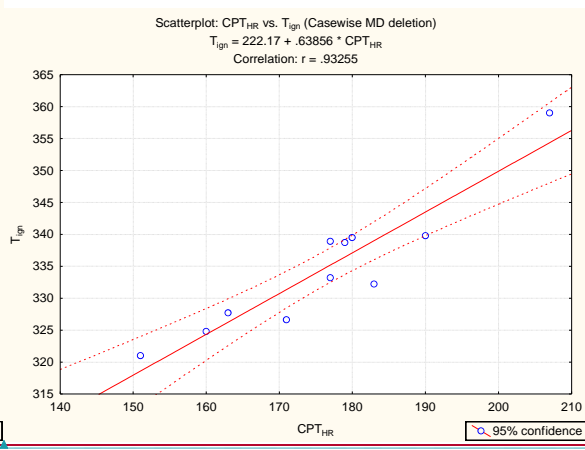

(d) CPTHR VS Tign
Fig. 7 Validation of spontaneous heating susceptibility indices from TGA experiments with standard CPT experiments Annexure -A

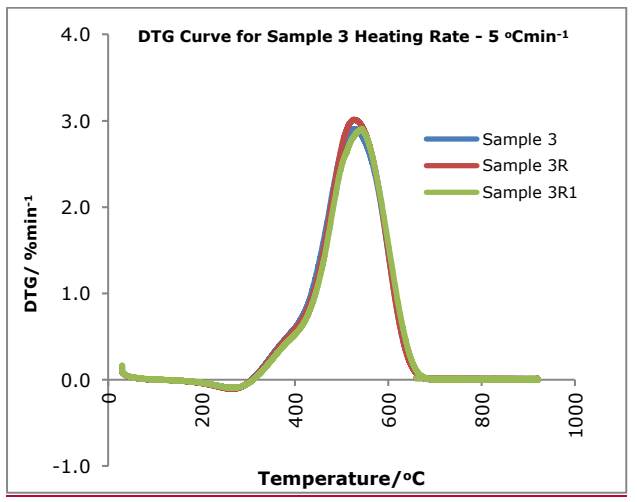

Formatted: Normal, Don't adjust space between Latin and Asian text, Don't adjust space between Asian text and

\section{Field Code Changed}

Field Code Changed

\section{Field Code Changed}

Field Code Changed 
Accepted for Publication January 2020: Journal of Thermal Analysis and Calorimetry https://doi.org/10.1007/s10973-019-09237-x
Formatted: Normal, Don't adjust space between Latin and Asian text, Don't adjust space between Asian text and

Fig. A1 Repeatability of sample 3 at heating rate $5^{\circ} \mathrm{Cmin}^{-1}$ 
Accepted for Publication January 2020: Journal of Thermal Analysis and Calorimetry https://doi.org/10.1007/s10973-019-09237-x

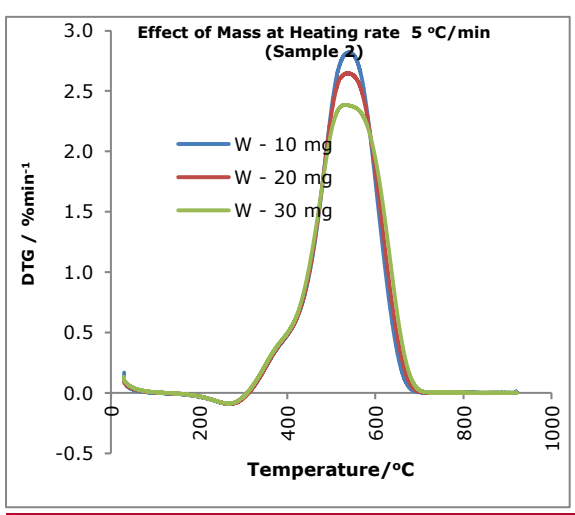

(a) Sample 2

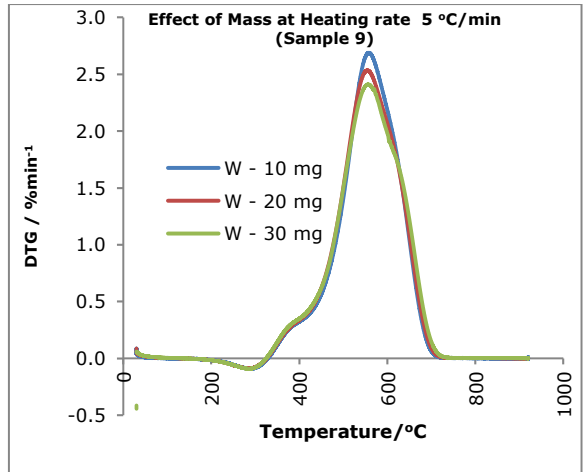

(e) Sample 9

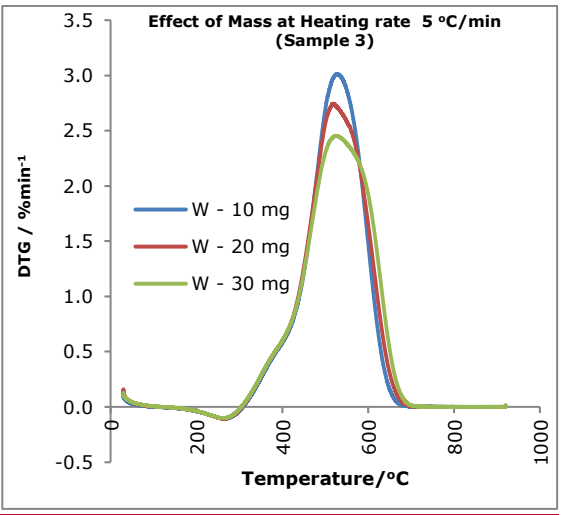

(b) Sample 3
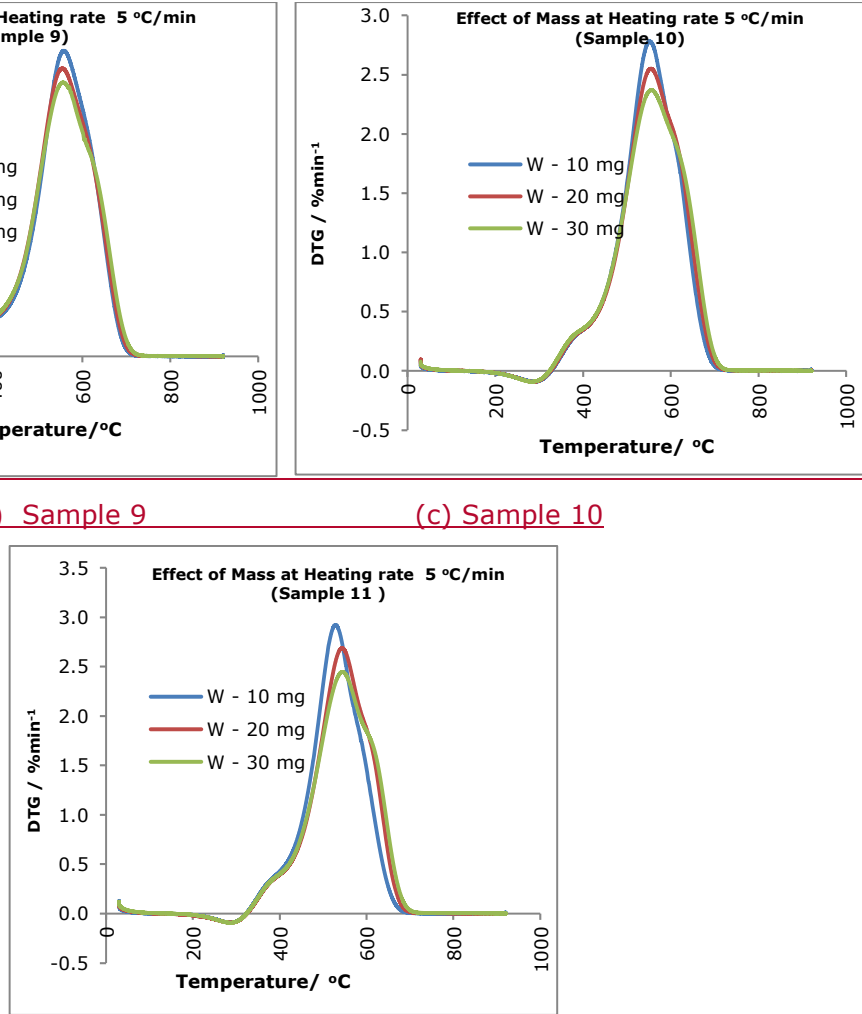

(d) Sample 11

Fig. A2 DTG curve for different mass of the sample $2,3,9,10 \& 11$
Formatted: Normal, Don't adjust space between Latin and Asian text, Don't adjust space between Asian text and 
Accepted for Publication January 2020: Journal of Thermal Analysis and Calorimetry https://doi.org/10.1007/s10973-019-09237-x

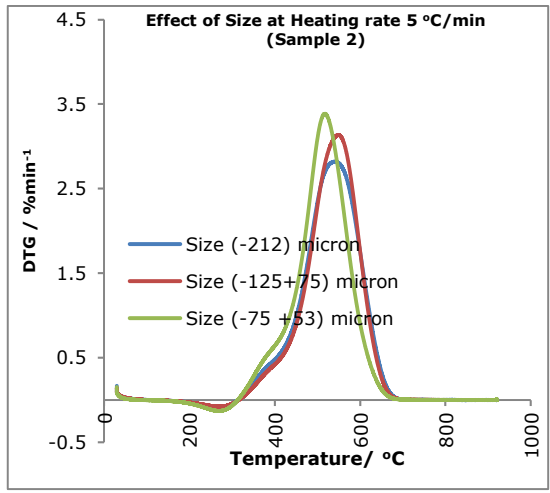

(a) Sample 2

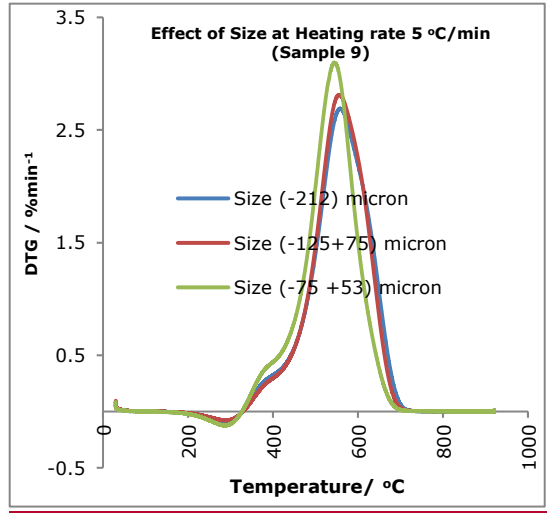

(c) Sample 9

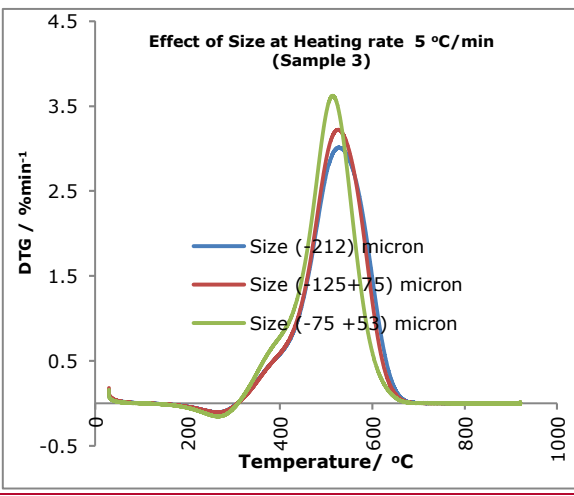

(b) Sample 3

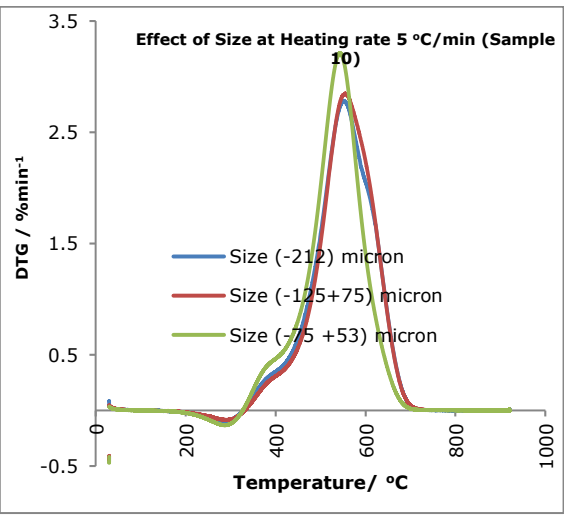

(d) Sample 10

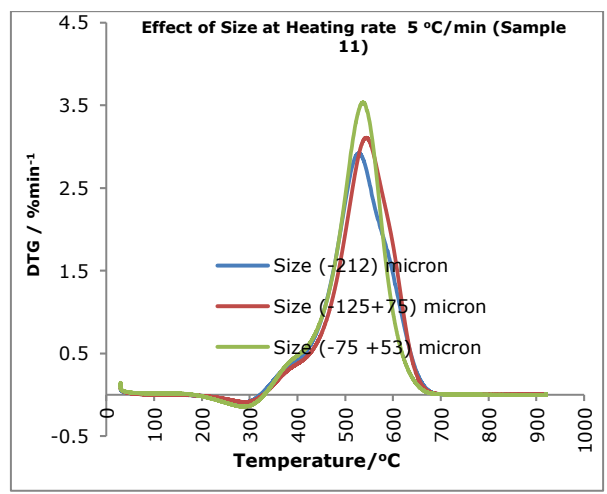

(e) Sample 11 
Accepted for Publication January 2020: Journal of Thermal Analysis and Calorimetry https://doi.org/10.1007/s10973-019-09237-x

Fig. A3 DTG curve for different fraction size of the sample 2, 3, 9, 10 \& 11
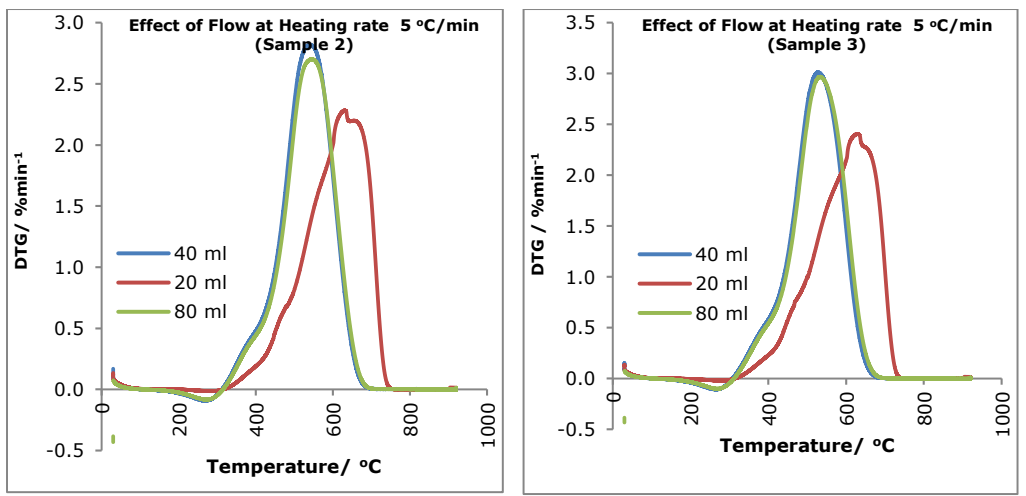

(a) Sample 2

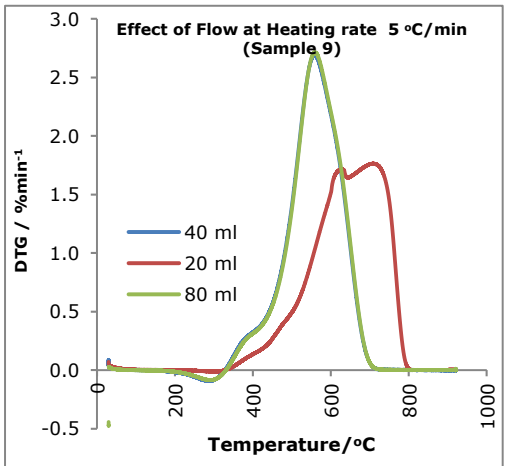

(b) Sample 3

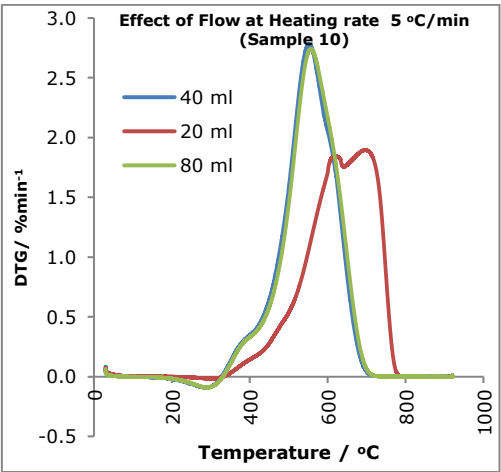

(c) Sample 9

(d) Sample 10

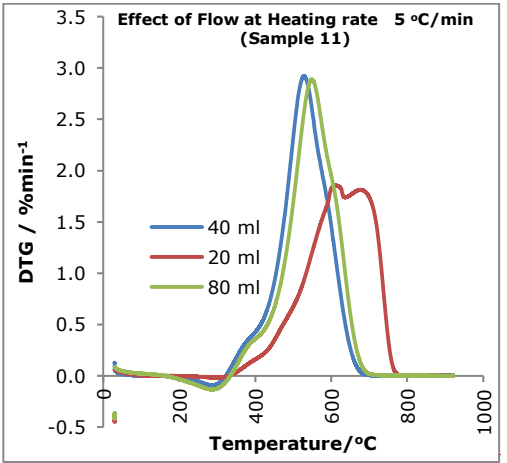

(e) Sample 11 
Accepted for Publication January 2020: Journal of Thermal Analysis and Calorimetry https://doi.org/10.1007/s10973-019-09237-x

Fig. A4 DTG curve for different flow rate of the sample $2,3,9,10 \& 11$

Table 1 Proximate, ultimate, petrographic analysis, CPT and CPTHR for coal samples

\begin{tabular}{|c|c|c|c|c|c|c|c|c|c|c|c|c|c|c|c|c|c|c|}
\hline $\begin{array}{c}\text { Sample } \\
\text { №. }\end{array}$ & $=\frac{\text { Seam and Mine }}{\text { Name }}$ & \begin{tabular}{|l|} 
Fire \\
Stat \\
us
\end{tabular} & $\begin{array}{l}\text { M/ } \\
\text { \%wt }\end{array}$ & $\frac{a l}{\frac{A l}{b t d}}$ & $\frac{V M I}{\% w t d b}$ & $\begin{array}{c}\mathrm{FC} / \\
\% \text { wtd b }\end{array}$ & \% $\frac{\mathrm{C} /}{w t d b}$ & $\begin{array}{l}\frac{H I}{\% w t} \\
\frac{d b}{d b}\end{array}$ & $\frac{\frac{N /}{\% w t}}{d b}$ & $\frac{S /}{\frac{S l}{d b}}$ & \%wtdb & $\frac{C P T_{X}}{{ }^{\circ} \mathcal{C}}$ & $\begin{array}{l}\text { CPT } \\
\underline{\text { COR }}\end{array}$ & $\begin{array}{l}\underline{v_{m} L} L \\
\underline{\%}\end{array}$ & $\begin{array}{l}\frac{L_{m}}{2} \\
\frac{\%}{0}\end{array}$ & $\frac{S F_{m} L}{\%}$ & $\begin{array}{l}\frac{F_{m} L}{\%} \\
\underline{\%}\end{array}$ & $\underline{V} \boldsymbol{R}_{\underline{m}}$ \\
\hline$\underline{1}$ & S-14 Chasnala & Yes & 1.14 & 10.43 & 27.49 & 62.07 & 69.11 & 4.41 & 1.37 & $\underline{0.25}$ & 14.42 & $\underline{145}$ & 160 & 67.2 & 2.4 & 21.6 & 3.6 & 0.74 \\
\hline$\underline{2}$ & S-14 Jitpur & Yes & $\underline{1.18}$ & 10.97 & 26.30 & 62.73 & 71.02 & 4.28 & 1.41 & 0.24 & $\underline{12.08}$ & $\underline{142}$ & $\underline{163}$ & $\underline{69.2}$ & $\underline{1.6}$ & $\underline{18.8}$ & $\underline{3.6}$ & 0.76 \\
\hline$\underline{3}$ & S-13 Chasnala & Yes & $\underline{1.16}$ & 7.87 & 29.89 & $\underline{62.24}$ & 73.57 & 4.87 & 1.45 & $\underline{0.28}$ & 11.96 & $\underline{136}$ & $\underline{151}$ & 62.4 & 1.6 & 10.4 & 9.2 & 0.87 \\
\hline 4 & S-16 Jitpur & Yes & 1.30 & 9.46 & 27.22 & 63.33 & 71.63 & 4.45 & 1.30 & $\underline{0.29}$ & 12.87 & $\underline{152}$ & 171 & 72.0 & 2.8 & 23.6 & 6.8 & 0.97 \\
\hline$\underline{5}$ & S-11 Enna & Yes & $\underline{0.61}$ & 21.07 & 21.27 & $\underline{57.66}$ & 64.17 & 3.96 & 1.28 & $\underline{0.00}$ & 9.52 & $\underline{169}$ & 207 & 40.4 & $\underline{0.8}$ & 27.2 & 6.0 & 1.00 \\
\hline$\underline{6}$ & S-11 Bhalgora & Yes & 1.22 & 16.91 & 23.48 & $\underline{59.61}$ & 69.76 & 4.20 & 1.56 & $\underline{0.45}$ & 7.12 & 171 & $\underline{183}$ & 74.4 & 3.2 & 26.4 & 4.0 & 1.02 \\
\hline$\underline{7}$ & S-11 Simlabahal & № & 1.25 & 13.57 & 23.53 & 62.90 & 70.96 & 4.05 & 1.50 & $\underline{0.35}$ & 9.57 & 159 & 177 & 55.2 & 1.2 & 27.2 & 8.8 & 1.15 \\
\hline 8 & S-12 Simlabahal & No & 1.13 & 16.93 & 21.94 & $\underline{61.13}$ & $\underline{66.45}$ & 4.00 & 1.37 & 0.41 & 10.84 & $\underline{152}$ & 177 & 74.8 & 5.6 & 36.0 & 7.6 & 1.08 \\
\hline$\underline{9}$ & S-10, Bhalgora & № & 0.64 & 17.30 & 20.56 & 62.14 & 69.41 & 3.92 & 1.57 & 0.29 & 7.51 & 165 & 190 & 68.4 & 1.2 & 46.0 & $\underline{12.8}$ & 1.04 \\
\hline$\underline{10}$ & S-10, Simlabahal & No & $\underline{0.63}$ & 16.86 & 20.86 & 62.29 & 69.96 & 4.12 & 1.58 & 0.32 & 7.17 & 168 & 180 & 57.2 & 1.2 & 32.0 & 9.6 & 1.05 \\
\hline$\underline{11}$ & S-09, Simlabahal & № & $\underline{0.92}$ & 17.04 & 22.42 & 60.54 & 69.30 & 4.10 & 1.66 & 0.41 & 7.50 & 162 & $\underline{179}$ & $\underline{64.8}$ & 2.0 & 25.2 & 4.0 & 1.09 \\
\hline
\end{tabular}

M- moisture, A-Ash, VM-Volatile matter, FC - Fixed carbon, C-Carbon, $\mathrm{H}$ - Hydrogen, $\mathrm{N}$-Nitrogen, S- Sulphur, O- Oxygen, CPTCrossing point temperature of coal, $C P T_{H R}-$ Modified Crossing point temperature of coal, $V_{m}-$ Vitrinite, $L_{m}-L_{m}$, Fusinite, $F_{\underline{m}}$-Fusinite, $V R_{\underline{m}}$ - Vitrinite Reflectance

Table 2 Correlations study between Spontaneous heating susceptibility indices with basic coal characteristics (significant at $p<.05000$ )

\begin{tabular}{|c|c|c|c|c|c|c|c|}
\hline & $C P T_{I}$ & $P T_{H R}$ & $\underline{T_{i r}}$ & $\underline{W}_{m w q}$ & $\underline{T_{m w q}}$ & $\underline{T_{s h}}$ & $\underline{T_{\text {iqn }}}$ \\
\hline & -0.57 & .66 & $\underline{0.39}$ & 0.12 & -0.62 & -0.72 & -0.73 \\
\hline & .86 & & $\underline{0.09}$ & -0.61 & 0.75 & 0.94 & 0.87 \\
\hline$V M_{d b}$ & -0.85 & -0.85 & -0.16 & 0.57 & -0.83 & -0.87 & -0.80 \\
\hline 58 & -0.55 & -0.69 & 0.07 & $\underline{0.46}$ & -0.31 & -0.71 & -0.68 \\
\hline & -0.51 & 0.76 & -0.04 & $\underline{0.48}$ & -0.43 & -0.76 & -0.76 \\
\hline$\underline{\boldsymbol{H}_{d b}}$ & -0.75 & -0.82 & -0.33 & $\underline{0.62}$ & -0.76 & -0.79 & -0.77 \\
\hline & $\underline{0.39}$ & $\underline{0.04}$ & $\underline{-0.06}$ & $\underline{-0.18}$ & $\underline{0.39}$ & $\underline{0.21}$ & $\underline{0.02}$ \\
\hline$\underline{S}_{d b}$ & $\underline{0.05}$ & $\underline{-0.31}$ & $\underline{0.21}$ & -0.46 & -0.04 & -0.21 & -0.47 \\
\hline$\underline{\boldsymbol{O}_{d b}}$ & -0.83 & $\underline{-0.64}$ & $\underline{-0.08}$ & $\underline{0.49}$ & -0.73 & -0.70 & -0.57 \\
\hline$\underline{v}_{m}$ & -0.30 & $\underline{-0.48}$ & -0.10 & -0.17 & -0.48 & -0.59 & -0.73 \\
\hline$\underline{L_{m}}$ & -0.16 & $\underline{-0.17}$ & $\underline{0.10}$ & -0.53 & $\underline{-0.31}$ & -0.17 & -0.36 \\
\hline$\underline{S F_{m}}$ & $\underline{0.64}$ & $\underline{0.65}$ & $\underline{0.19}$ & -0.44 & $\underline{0.59}$ & $\underline{0.58}$ & $\underline{0.49}$ \\
\hline III & $\underline{0.15}$ & $\underline{0.17}$ & $\underline{0.12}$ & $\underline{0.14}$ & $\underline{0.31}$ & $\underline{0.20}$ & $\underline{0.16}$ \\
\hline$\underline{V} \boldsymbol{R}_{m}$ & $\underline{0.69}$ & 0.60 & 0.56 & -0.63 & 0.81 & $\underline{0.70}$ & 0.54 \\
\hline
\end{tabular}


Accepted for Publication January 2020: Journal of Thermal Analysis and Calorimetry https://doi.org/10.1007/s10973-019-09237-x

Table 3 Eigenvalues of correlation matrix between Spontaneous heating susceptibility indices with basic coal characteristics

\begin{tabular}{|c|c|c|c|c|}
\hline Sl. No. & Eigenvalue & \% Total & Cumulative & Cumulative \\
\hline$\underline{1}$ & 10.67621 & 50.83909 & 10.67621 & 50.8391 \\
\hline$\underline{2}$ & 3.60160 & 17.15045 & 14.27780 & $\underline{67.9895}$ \\
\hline$\underline{3}$ & 2.52588 & 12.02802 & 16.80369 & $\underline{80.0176}$ \\
\hline 4 & 1.54092 & 7.33771 & 18.34461 & 87.3553 \\
\hline$\underline{5}$ & 1.32703 & 6.31920 & 19.67164 & 93.6745 \\
\hline$\underline{6}$ & 0.55462 & 2.64105 & 20.22626 & 96.3155 \\
\hline$\underline{7}$ & $\underline{0.35072}$ & 1.67011 & 20.57698 & 97.9856 \\
\hline$\underline{8}$ & 0.23908 & 1.13847 & 20.81606 & 99.1241 \\
\hline$\underline{9}$ & $\underline{0.09594}$ & $\underline{0.45686}$ & 20.91200 & $\underline{99.5810}$ \\
\hline 10 & 0.08800 & 0.41905 & 21.00000 & 100.0000 \\
\hline
\end{tabular}

Table 4 Results of the clustering of the coal sample data sets from the dendograms

\begin{tabular}{|c|c|c|c|c|c|c|c|}
\hline $\begin{array}{l}\text { No. of } \\
\text { clusters }\end{array}$ & $\underline{C P T_{I}}$ & $\underline{\mathrm{CPT}_{H R}}$ & $\underline{\boldsymbol{T}_{\text {ir }}}$ & $\underline{W}_{m w g}$ & $\underline{\boldsymbol{T}}_{m w g}$ & $\underline{T}_{s h}$ & $\underline{T_{i g n}}$ \\
\hline Cluster 1 & $\underline{1,2,3,4}$ & $\underline{1,2,3,4}$ & $\begin{array}{l}1,2,3,4,6,8,9,10, \\
\underline{11}\end{array}$ & $\begin{array}{l}1,2,3,4,6,7,10,1 \\
\underline{1}\end{array}$ & $\begin{array}{l}\underline{1,2,3,4,6,} \\
\underline{8}\end{array}$ & $1,2,3,4$ & $\underline{1,2,3,4}$ \\
\hline Cluster 2 & $\underline{6,7,8,9,10,11}$ & $\begin{array}{l}6,7,8,9,10,1 \\
\underline{1}\end{array}$ & $\underline{5}$ & 8,9 & $5,7,10,11$ & $\underline{\underline{6}, 7,8,9,10,1}$ & $\begin{array}{l}6,7,8,9,10,1 \\
\underline{1}\end{array}$ \\
\hline Cluster 3 & $\underline{5}$ & $\underline{5}$ & $\underline{7}$ & $\underline{5}$ & $\underline{9}$ & $\underline{5}$ & $\underline{5}$ \\
\hline
\end{tabular}

Table 5 Correlations study between spontaneous heating susceptibility indices

\begin{tabular}{|c|c|c|c|c|c|c|c|}
\hline & CPTI & $\mathrm{CPT}_{H R}$ & $\underline{\boldsymbol{T}_{i r}}$ & $\underline{W}_{m w g}$ & $\underline{I}_{\text {mwg }}$ & $\underline{T_{s h}}$ & $\underline{T_{i g n}}$ \\
\hline$\underline{C P T_{I}}$ & 1.00 & & & & & & \\
\hline$C P T_{H R}$ & 0.87 & 1.00 & & & & & \\
\hline$\underline{T_{\text {ir }}}$ & 0.24 & 0.23 & 1.00 & & & & \\
\hline$\underline{\boldsymbol{W}}_{m w g}$ & -0.56 & -0.50 & -0.56 & 1.00 & & & \\
\hline$\underline{T}_{m w g}$ & $\underline{0.77}$ & $\underline{0.78}$ & 0.31 & -0.35 & 1.00 & & \\
\hline$\underline{T}_{s h}$ & 0.82 & $\underline{0.91}$ & 0.21 & -0.50 & 0.84 & 1.00 & \\
\hline$\underline{T}_{i g n}$ & $\underline{0.76}$ & 0.93 & 0.20 & -0.35 & 0.81 & 0.94 & 1.00 \\
\hline
\end{tabular}


Accepted for Publication January 2020: Journal of Thermal Analysis and Calorimetry https://doi.org/10.1007/s10973-019-09237-x

Table A1 TGA results

\begin{tabular}{|c|c|c|c|c|c|c|c|c|c|c|c|c|c|c|c|c|c|c|c|c|}
\hline \multirow{2}{*}{$\begin{array}{l}\text { Sample } \\
\text { No. }\end{array}$} & \multicolumn{4}{|c|}{$I_{i r} / l^{\circ} \mathrm{C}$} & \multicolumn{4}{|c|}{$\underline{W}_{m w a} / \%$} & \multicolumn{4}{|c|}{$I_{m w q} /{ }^{\circ} \mathrm{C}$} & \multicolumn{4}{|c|}{$I_{s h /}{ }^{\circ} \mathrm{C}$} & \multicolumn{4}{|c|}{$I_{\text {ign }} /\left(^{\circ} \mathrm{C}\right)$} \\
\hline & HR 1 & HR 5 & HR 15 & HR 30 & HR 1 & HR 5 & HR 15 & HR 30 & HR 1 & HR 5 & HR 15 & HR 30 & HR 1 & HR 5 & HR 15 & HR 30 & HR 1 & HR 5 & HR 15 & HR 30 \\
\hline 1 & 104.9 & 130.6 & 178.1 & $\begin{array}{ll}195.8 \\
\end{array}$ & 2.85 & 1.59 & 0.93 & 0.60 & 289.0 & 321.0 & 342.2 & 352.8 & 241 & 264 & 302 & $\underline{318}$ & 337.4 & 324.8 & 349.8 & 357.3 \\
\hline 2 & 105.0 & 125.3 & 148.3 & 190.1 & 2.79 & 1.49 & 0.95 & 0.53 & 293.1 & 325.0 & 345.4 & 356.6 & 273 & 260 & 299 & $\underline{312}$ & 340.3 & 327.7 & 352.0 & 359.4 \\
\hline 3 & $\underline{106.0}$ & $\underline{122.6}$ & 143.7 & $\underline{184.3}$ & 3.19 & $\underline{1.73}$ & 1.10 & $\underline{0.68}$ & 288.1 & $\underline{321.1}$ & 340.5 & 350.3 & $\underline{249}$ & $\underline{261}$ & $\underline{295}$ & $\underline{306}$ & 331.7 & 321.0 & 347.2 & 354.7 \\
\hline 4 & 105.5 & 155.8 & $\underline{175.0}$ & $\underline{194.9}$ & 2.89 & $\underline{1.51}$ & $\underline{0.95}$ & $\underline{0.52}$ & 293.0 & 331.0 & 345.0 & 360.8 & $\underline{243}$ & $\underline{263}$ & $\underline{300}$ & $\underline{313}$ & 340.4 & 326.6 & 351.4 & 357.8 \\
\hline$\underline{5}$ & 110.7 & 145.0 & $\underline{190.3}$ & 205.0 & 2.28 & 1.26 & 0.86 & 0.46 & 310.0 & 340.6 & 364.2 & 374.9 & 274 & 302 & $\underline{322}$ & 331 & 373.0 & 359.0 & 368.5 & 378.3 \\
\hline 6 & $\underline{132.5}$ & 155.9 & 249.2 & $\underline{275.8}$ & 1.99 & 0.80 & 0.35 & 0.09 & 302.2 & 328.6 & 341.1 & 350.5 & 267 & $\underline{278}$ & $\underline{309}$ & $\underline{322}$ & $\underline{346.9}$ & 332.2 & 353.6 & 357.4 \\
\hline 7 & 153.0 & 213.7 & 236.1 & $\underline{285.2}$ & $\underline{2.11}$ & 1.08 & 0.47 & $\underline{0.19}$ & 305.0 & 339.3 & 355.4 & $\underline{358.1}$ & $\underline{275}$ & $\underline{281}$ & $\underline{312}$ & $\underline{317}$ & 355.9 & 338.9 & 359.5 & 363.3 \\
\hline 8 & $\underline{126.1}$ & 154.1 & 235.1 & 269.5 & 1.93 & 0.85 & 0.42 & 0.18 & 298.0 & 331.0 & 346.3 & 356.6 & 282 & $\underline{281}$ & 311 & 324 & 352.1 & 333.2 & 355.5 & 356.5 \\
\hline 9 & 117.1 & 139.7 & 142.7 & 196.8 & 2.69 & 1.38 & 0.92 & 0.52 & 306.3 & 338.5 & 361.0 & 372.5 & $\underline{270}$ & $\underline{284}$ & 325 & 324 & 360.5 & 339.8 & 365.0 & 372.6 \\
\hline 10 & 127.1 & $\underline{118.9}$ & 188.8 & 201.2 & 2.61 & 1.48 & 0.91 & 0.53 & 308.4 & 339.0 & 358.9 & 370.0 & $\underline{284}$ & $\underline{284}$ & 320 & 330 & 360.0 & 339.5 & 364.9 & 373.4 \\
\hline$\underline{11}$ & 113.9 & 134.3 & $\underline{171.7}$ & $\underline{229.2}$ & 2.52 & 1.23 & 0.89 & 0.40 & 307.7 & 342.8 & 357.8 & 368.3 & $\underline{276}$ & $\underline{287}$ & $\underline{325}$ & 329 & 353.3 & 338.7 & 360.1 & 369.3 \\
\hline
\end{tabular}

Formatted: Normal, Don't adjust space between Latin and Asian text, Don't adjust space between Asian text and Height: $21.59 \mathrm{~cm}$ 